\title{
Service Systems, Service Scientists, SSME, and Innovation (20060330 v1)
}

\author{
Paul P. Maglio, Savitha Srinivasan, Jeffrey T. Kreulen, and Jim Spohrer
}

IBM Research

\begin{abstract}
Computer scientists work with formal models of algorithms and computation, and someday service scientists may work with formal models of service systems, which we define as value creation networks composed of people, technology, and organizations. In this paper, we briefly consider four examples of service systems - education, IT service delivery centers, call centers, and patents—and we document some of the early efforts to establish a new academic discipline (SSME: Services Sciences, Management, and Engineering) and new profession (service scientist) to focus on the challenge of making innovation in services more systematic.
\end{abstract}

\section{Introduction}

The global economy is a large service system in need of innovation to grow (see Table 1).

\begin{tabular}{|c|c|c|c|c|c|}
\hline$\underline{\text { Nation }}$ & $\frac{\text { World Labor }}{\underline{\text { \% of total })}}$ & $\frac{\text { Agriculture }}{\underline{\%}}$ & $\frac{\text { Goods }}{\underline{\%}}$ & $\frac{\text { Services }}{\underline{\%}}$ & $\frac{\text { Services growth }}{\frac{(\% \text { increase in }}{\text { last } 25 \text { years })}}$ \\
\hline China & 21.0 & 50 & 15 & 35 & 191 \\
\hline India & 17.0 & 60 & 17 & 23 & 28 \\
\hline U.S. & 4.8 & 3 & 27 & 70 & 21 \\
\hline Indonesia & 3.9 & 45 & 16 & 39 & 35 \\
\hline Brazil & 3.0 & 23 & 24 & 53 & 20 \\
\hline Russia & 2.5 & 12 & 23 & 65 & 38 \\
\hline Japan & 2.4 & 5 & 25 & 70 & 40 \\
\hline Nigeria & 2.2 & 70 & 10 & 20 & 30 \\
\hline Bangladesh & 2.2 & 63 & 11 & 26 & 30 \\
\hline Germany & 1.4 & 3 & 33 & 64 & 44 \\
\hline
\end{tabular}

Table 1: The economies of the world are shifting labor from agriculture and manufacturing into services, as measured by percentage of labor (jobs) in each sector. Source: http://www.nationmaster.com.

Service systems are value creation networks composed of people, technology, and organizations (see Figure 1). Interventions taken to transform state and coproduce value constitute services. For instance, in information technology (IT) outsourcing services, a service provider operates the computing infrastructure for a service client. The provider augments the client's capabilities, taking on responsibility for monthly service level agreements and year-over-year productivity improvements. The formal representation and modeling of service systems is nascent, largely because of the complexity of modeling people, their knowledge, activities, and intentions. Service system complexity is a function of the number and variety of people, technologies, and organizations linked 
in the value creation networks, ranging in scale from professional reputation systems of a single kind of knowledge worker or profession [1], to work systems composed of multiple types of knowledge workers [10], to enterprise systems (e.g., businesses) [3], to industrial systems [4], to national systems [5], and ultimately to the global service system [2]. Knowledge workers depend on their knowledge, tools, and social-organizational networks to solve problems, be productive, continually develop, and generate and capture value.

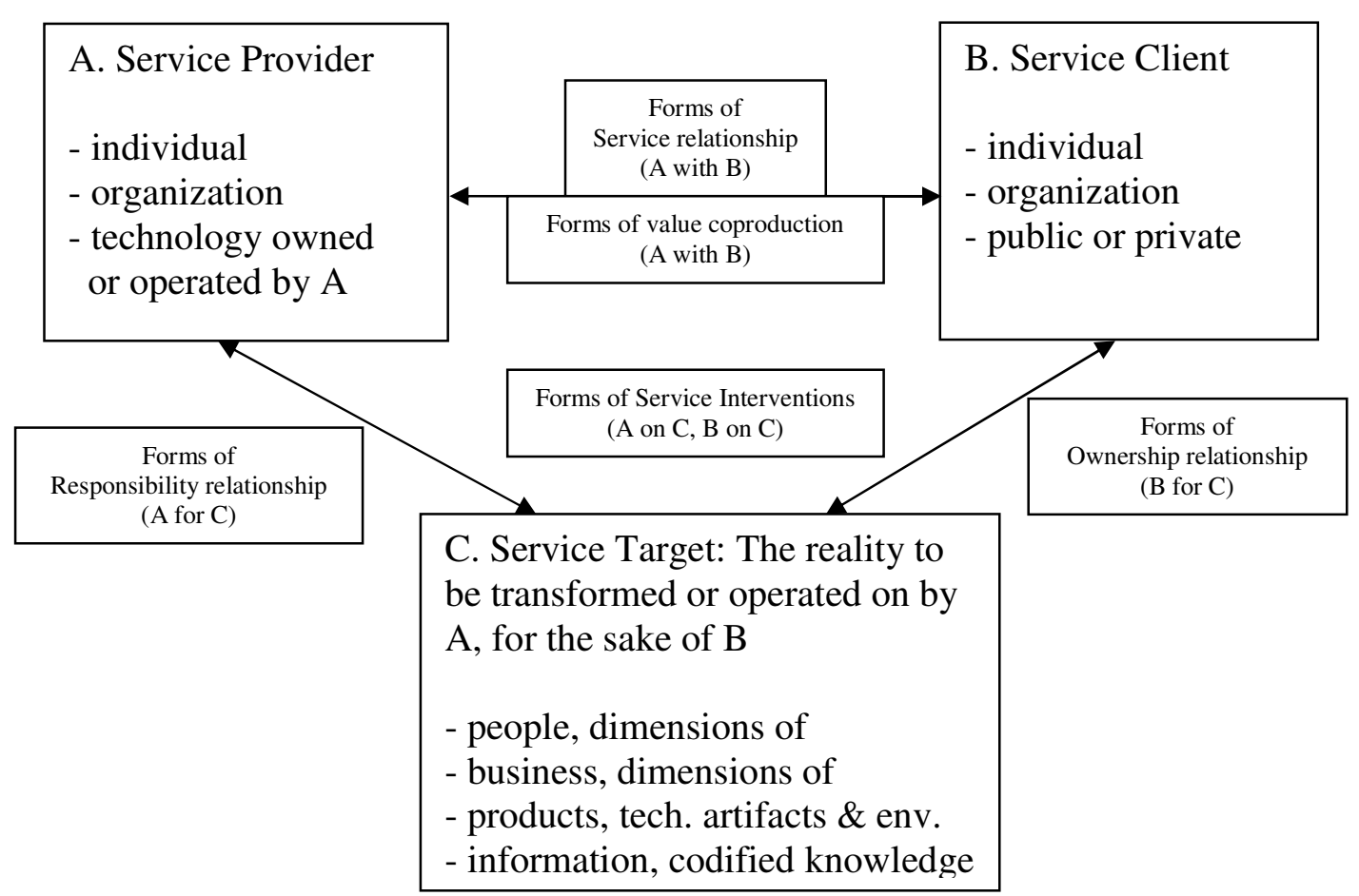

Figure 1: The definition of services in terms of relationships and actions among service provider, service client, and service target, based on [7].

Formal representation and measurement of work in service systems is a grand challenge for the services economy (see Table 2).

\begin{tabular}{|l|l|l|l|}
\hline & \multicolumn{1}{|c|}{ 1800's } & \multicolumn{1}{c|}{ 1900's } & \multicolumn{1}{c|}{ 2000's } \\
\hline Notion of Work & Physical System & Information System & Service System \\
\hline $\begin{array}{l}\text { What is } \\
\text { transformed }\end{array}$ & Matter and Energy & Information & $\begin{array}{l}\text { People, } \\
\text { Technologies, } \\
\text { Organizations, } \\
\text { Information }\end{array}$ \\
\hline $\begin{array}{l}\text { Example } \\
\text { (Measurement) }\end{array}$ & $\begin{array}{l}\text { Steam engine } \\
\text { (Mass, Distance, } \\
\text { Time) }\end{array}$ & $\begin{array}{l}\text { Search engine } \\
\text { (Computational } \\
\text { Complexity) }\end{array}$ & $\begin{array}{l}\text { Off shore call center } \\
\text { (Time, Cost, Skill } \\
\text { level) }\end{array}$ \\
\hline
\end{tabular}




\begin{tabular}{|l|l|l|l|}
\hline $\begin{array}{l}\text { Compliance } \\
\text { Laws }\end{array}$ & Physical & $\begin{array}{l}\text { Logical and } \\
\text { Mathematical }\end{array}$ & $\begin{array}{l}\text { Legal, Cultural, and } \\
\text { Contractual }\end{array}$ \\
\hline
\end{tabular}

Table2 : Three eras and three perspectives on measurement of work. At the start of each century, the formal representation and measurement of work in each system became the focus of scientific attention.

We do not yet know how best to measure work and knowledge value reconfiguration in service systems. To illustrate the complexity of formally modeling services systems, consider four examples: education, IT service delivery centers, call centers, and patents.

Example 1: Education as a Service System: Education is fundamental in any society. The educational system transforms young people with general literacy skills into entrylevel professionals (knowledge workers). After the dot-com bubble burst and outsourcing of IT jobs to India became a common headline in newspapers, many universities in the US and Canada witnessed sharp drops in enrollment for Computer Science. The directors of Computer Science departments, who had seen increasing demand for several decades, were now facing three problems: (1) faculty complained of fewer, less able students entering their classrooms, (2) industry complained of a poorer match between the needs of business and the computer science graduates being produced, and (3) faculty recruiting and morale were declining on some campuses.

How might a service scientist approach the problem of creating service innovations and improving the educational service system? First, the service scientist might identify the stakeholders and interview them to learn of the boundaries of the service system and of any problems and opportunities that the stakeholders see. Second, a service scientist might create a formal model of the service system, including a table of all stakeholder interactions, what technologies and organizations mediate those interactions, and who owns or does not own the perceived problems and opportunities. To be clear, the challenge lies not simply in formally modeling the technology or organizational interactions, but in modeling the people and their roles as knowledge workers in the system. Traditional modeling assumes people are either (a) like machines or other resources, (b) different in that they can be modeled as a set of skills that change with experience, or (c) different in that they form relationships and social networks to improve productivity.

The third step for a service scientist might be to extrapolate the year-over-year evolution of the system and the hour-by-hour activities of stakeholders. A service scientist might then envision new service systems that could be put in place to solve each problem. Sometimes the needed service systems are well known, and financial investment is all that is needed - new stakeholders are added. Or perhaps leaders can encourage existing stakeholders to multitask on new activities - requiring that existing stakeholders do more to enhance their professional reputations. In this way, a service scientist might solve known problems by connecting new service systems to the problematic aspects of the original service system. For example, consider the following revision to the educational system: 
(1) Each year $20 \%$ of the faculty activities in the classroom should be converted to upfront elearning that students must pass to enroll in the class. Year over year, this will ensure a higher level of capability for students entering the classroom. The new service system, an augmentation, is required to engage faculty and other stakeholders to identify the $20 \%$ of the classroom activity to be freed up, and embed these curricular components into the elearning certification system.

(2) Half of the freed up faculty time will be replaced with new course material designed to better meet the needs of industry. The second added service system will engage industry and faculty to create the needed curriculum changes.

(3) Half of the freed up faculty time will be replaced with new course material designed to meet the needs of the faculty for more intellectually stimulating content and meaningful work experience.

In this scenario, the original service system is improved by connecting three new service systems. The resulting composite system would be more adaptive, sense more of its environment, and respond more appropriately. At 20\% year-over-year compounding, the service system might be dramatically different in just five years. Of course, many challenges remain. For example, what is the incentive for old stakeholders and the new stakeholders to work together? Leaders may motivate some stakeholders to step up and take on additional responsibilities to boost their reputations, a financial incentive may be put in place, or policy or laws might be put in place to ensure the changes are made. In general, when stakeholders adjust the boundaries of their service system, new business opportunities (or knowledge value capture points) arise [3].

Example 2: IT Service Delivery Centers as a Service System: We studied IT service delivery in a series of field visits conducted in data centers of large IT service providers. In 14 visits, we observed and interviewed more than 30 administrators, team leads, and managers over 50 days [8]. Our goal was to examine the work practices, tools, and organizational structures in IT service delivery. For instance, we observed Shawn, an operating system administrator work with clients and others in his organization to manage the patches for Unix systems for an enterprise client. Shawn told us that many servers are patched given special considerations. He explained that negotiations with clients take a lot of time. Though provider and client agreed that all servers would be patched every 120 days, in practice most patches need to be negotiated individually. Despite formal processes and communication channels (e.g., ticket system), Shawn relies on informal communication (e.g. email, phone calls) to take special considerations into account and to plan his work.

In this and in many other cases, informal work is prevalent in IT operations because of the complicated relationship among businesses, organizations, and technologies. In fact, our studies show that informal work activities account for much system administrator time [8]. These informal activities include negotiating work items and schedules, seeking and providing information and expertise, and using and sharing tools and practices. Informal activities are conducted outside formal IT service processes and tooling, making them a kind of inefficient add-on - they are almost never considered in cost analyses and 
almost never supported with tools or technologies. Yet by studying human coordination in the field, we identified several opportunities for injecting technology into the system to make IT service delivery more effective. For instance, we developed a platform for scripting and sharing scripts within the service system - transforming existing informal activities into supported activities.

Example 3: Call Centers as a Service System: Call centers are another example of a service system. They employ over 6 million people in North America alone. Over \$100B in labor costs are incurred in call centers. Though upsell and cross-sell opportunities have been explored, most companies view call centers as cost centers to be controlled or reduced. From a service provider's perspective, the economic model for a call center is very simple: (1) stop incoming calls if possible; (2) if the call must be taken, minimize time to resolve the call; (3) if the problem cannot be resolved by phone, dispatch service at lowest labor cost.

The stakeholders in the call center system include (1) the customer that has outsourced its helpdesk, (2) the service provider, (3) call takers, (4) individual account, (5) schedulers, and (6) the quality management team. Each stakeholder has distinct goals. The customer seeks a reliable service provider that provides cost-effective, high-quality service. The service provider seeks to increase revenue, reduce cost, and maximize profit while overachieving on its service-level agreements (SLAs). Call takers vary in skill and responsibility (from $\$ 10$ an hour to $\$ 100$ an hour) and have many considerations, ranging from customer satisfaction, ease of use of tools, first call resolution successes, and managing call volumes. Individual account managers have responsibility for specific accounts and aim for account customer satisfaction, ensuring proactive action before call volumes turn into critical situations that may jeopardize SLAs. Schedulers within the provider organization forecast demand based on statistics and SLA agreements, and provide input to the planners to ensure optimal coverage to meet SLAs given expected variance in call volumes. The quality management team monitors the quality of calls, focusing on the bottom $25 \%$ and top $25 \%$ to try to continually improve effectiveness.

Analysis of the stakeholders, their pain points, and their measurements reveals that the entire system can benefit by taking an end-to-end view, focusing on transforming the system by introducing appropriate processes, metrics, technology, and tools to work in concert across stakeholders. The transformation must be executed as a combination of process changes, organizational changes, technology changes, and tool changes. As an example, if one area of high cost is the volume of calls routed from level 1 (basic, inexpensive call takers) to level 3 (highly skilled, expensive call takers), several corrective actions may be taken. The problems that flow to level 3 can be better understood and level 1 call takers can be trained in those problem areas. In addition, tools may be improved to provide answers to those classes of problems and self-service for end users can also be introduced.

Example 4: Patents as a Service System: Models and analytical methods for service systems will allow us to find opportunities for efficiency gains and to create new information-based services [9]. Consider the worldwide intellectual property system - 
the patent system - as a service system. Stakeholders include inventors, invention assignees (people or firms that own the rights to the invention), consumers who use the inventions, the nation or nations under jurisdiction of the patenting authority, and the patent authorities themselves. Each actor has different goals. Inventors want it to be easy to file patents and to find prior-art. Assignees want to keep the cost down, simplify the use of the system, minimize the cost of conflict resolution, and maintain ownership of the invention to gain the most economic reward. Consumers are the indirect beneficiaries of a fair system that encourages innovation in a cost-effective manner through availability of better and cheaper consumables. Nations are interested in the net effect of systemic innovation resulting in a larger gross domestic product (GDP) and a thriving economy. Patent authorities are responsible for cost, execution, and fairness of the system. Measures that affect all these stakeholders include cost, quality of patents, systemic ease of use, fairness, prior-art search, speed, and conflict resolution.

Analyzing this service system requires understanding and optimization of the patenting process itself. Additionally, the nature of patents requires the use of structured and unstructured information analytics because the primary artifact is the patent, which is largely an unstructured document that describes the invention. Analysis of patents will allow for improving quality and prior-art search. However, the purpose of this system is to encourage economic vitality. So the true measure of success is its net effect on an economy and on the stakeholders within it to produce and capture the value from their innovations. This example points to the interconnectedness of all service systems, and the need to identify boundaries, stakeholders, problems, and opportunities.

\section{Concluding Remarks}

Many businesses are intrigued by the notion of hiring service scientists. Service scientists will study, manage, and engineer service systems, solving problems and exploiting opportunities to create service innovations. Researchers, educators, and practitioners show tremendous interest in understanding service systems, and in the potential of establishing the new academic discipline, Services Sciences, Management, and Engineering (SSME) ${ }^{1}$. For example, the University of California, Berkeley, recently announced a graduate-level certificate in SSME for students in business, engineering, and information science. ${ }^{2}$ Other University of California programs are scheduled to start in Fall 2006. North Carolina State University recently announced a services sciences concentration for its MBA program, along with service-related courses being incorporated into specific computer science and engineering degrees. ${ }^{3}$ Other universities and institutes are pursuing aspects of services research and services education (see Table $3)$.

\footnotetext{
${ }^{1}$ To simplify, science is a way to create knowledge, engineering is a way to use knowledge to create value, and management invests to improve the process of creating and capturing value.

${ }^{2}$ See http://www.citris-uc.org/publications/newsletter/february2006\#feature2

${ }^{3}$ See http://www.mgt.ncsu.edu/news/2006/mba_ssme.php
} 


\begin{tabular}{|l|l|}
\hline Arizona State University & $\begin{array}{l}\text { Center for Services Leadership } \\
\text { http://wpcarey.asu.edu/csl/ }\end{array}$ \\
\hline UC Berkeley & $\begin{array}{l}\text { Operations Research and Management Science } \\
\text { http://www.ieor.berkeley.edu/AcademicPrograms/Ugrad/ORMS.pdf }\end{array}$ \\
\hline Carnegie Mellon University & $\begin{array}{l}\text { Masters in Information Systems } \\
\text { http://www.mism.cmu.edu/ } \\
\text { Masters in Science in Information Systems Technology } \\
\text { http://www.msit.cmu.edu/ }\end{array}$ \\
\hline Fraunhofer Institute & $\begin{array}{l}\text { Industrial Engineering \& Service Engineering } \\
\text { http://www.dienstleistung.iao.fraunhofer.de/english/Overview.pdf }\end{array}$ \\
\hline Georgia Institute of Technology & $\begin{array}{l}\text { Tennenbaum Institute for Enterprise Transformation } \\
\text { http://www.ti.gatech.edu/ }\end{array}$ \\
\hline Massachusetts Institute of & $\begin{array}{l}\text { Engineering Systems Division } \\
\text { http://esd.mit.edu// } \\
\text { Sloan School of Management } \\
\text { http://www.sciencemasters.com/index.html }\end{array}$ \\
\hline North Carolina State University & $\begin{array}{l}\text { Center for Innovation Management Studies } \\
\text { http://cims.ncsu.edu/index.php }\end{array}$ \\
\hline Penn State University & $\begin{array}{l}\text { School of Information Science and Technology } \\
\text { http://ist.psu.edu }\end{array}$ \\
\hline Rensselaer Polytechnic Institute & $\begin{array}{l}\text { Center for Service Research and Education } \\
\text { http://www.dses.rpi.edu/research/csre.cfm }\end{array}$ \\
\hline University of Maryland & $\begin{array}{l}\text { Center for Excellence in Service } \\
\text { http://www.rhsmith.umd.edu/ces/membershiplevels.html }\end{array}$ \\
\hline
\end{tabular}

Table 3. Some existing university programs and centers related to SSME.

\section{References}

1. Abbott, Andrew (1988) The system of professions: An essay on the division of expert labor. University of Chicago Press. Chicago. IL

2. Bryson, John R., Peter W Daniels, Barney Warf (2004) Service worlds: People, technology, organizations. Routledge. London.

3. Rouse, William (2006) Enterprise transformation: Understanding and enabling fundamental change. Wiley Interscience. Hoboken, NJ.

4. Baldwin, Carliss Y. and Clark, Kim B. (2000) Design Rules, Vol. 1: The Power of Modularity. MIT Press. Cambridge, MA.

5. Lewis, William W. (2004) The power of productivity: Wealth, poverty, and the threat to global stability. University of Chicago Press. Chicago, IL.

6. Tamura, Shuji, Sheehan, Jerry, Martinez, Catalina, and Kergroach, Sandrine (2005) Promoting Innovation in Services. Organization for Economic Co-operation and Development (OECD). DSTI/STP/TIP(2004)4/Final. JT00191834.

7. Gadrey, Jean (2002) The misuse of productivity concepts in services: lessons from a comparison between France and the United States. In Productivity, Innovation and 
Knowledge in Services : New Economic and Socio-Economic Approaches. Editors, Jean GadreyGadrey, Jean, Gallouj, Faiz. Edward Elgar Publisher.

8. Barrett, R., Kandogan, E., Maglio, P. P., Haber, E., Takayama, L., \& Prabaker, M. (2004). Field Studies of Computer System Administrators: Analysis of System Management Tools and Practices. In Proc. of the ACM Conference on Computer Supported Cooperative Work (CSCW'04).

9. H. Hacigumus, J. Rhodes, W. Spangler, J. Kreulen, BISON: Providing Business Information Analysis as a Service, to appear in Proceedings of EDBT 2006.

10. Alter, Steven (2006) The Work System Method: People, Process, and Technology. Unpublished manuscript available by request to author (http://www.stevenalter.com/). 